\title{
ANDRÉS BELLO Y EL POEMA DEL CID
}

En los angustiosos años de su permanencia en Londres (1810-1829), Bello encuentra, para alivio de sus dolores y preocupaciones, un refugio en las salas del Museo Británico, donde no tarda en descubrir inmensos tesoros bibliográficos con que satisfacer su vehemente deseo de estudiar, de aprender y de ampliar su ya notable cultura.

Fue también en el Museo Británico donde, hacia 1817, tomó contacto con la Gesta o Cantar de Mio Cid, aquella obra maestra de la literatura arcaica española que Tomás Antonio Sánchez descubriera y editara, por primera vez, en 1779. Bello halló reparos que formular a la edición de Sánchez, quien dejó el texto en "lastimoso estado de corrupción", y se propuso emprender la reconstrucción del Poema, restituirle su forma primitiva, que él intuía con gran lucidez.

Nacían tan vastos proyectos en su espíritu ya desde los primeros años en Londres y parece que el estudio del Poema fue una de las principales tareas que ocupara su atención. Sabemos, por una carta dirigida por Bello, en junio de 1863, al, en aquel entonces, Secretario de la Real Academia Española, don Manuel Bretón de los Herreros, que la preparación de su obra sobre el Cid ya estaba muy avanzada hacia 1834 , pero que, a partir de esta fecha, diversas otras ocupaciones atrajeron la atención de su autor, quedando, así, la obra inconclusa hasta 1862, fecha en la cual decide completarla. Pero Bello muere sin darle los retoques últimos a la edición que, como lo demuestran las indagaciones de don Pedro Grases, preocupó la mente de don Andrés durante un espacio de casi cincuenta años de su vida (v. Andrés Bello. El primer humanista de América, Buenos Aires, 1946).

En Chile, Bello no dispuso de las obras de consulta ni de los elementos de estudio que le ofreciera el Museo Británico, de modo que tuvo que contentarse con el material y las noticias que traía de Inglaterra. En vista de estas circunstancias desfavorables para completar y enmendar su tra- 
bajo, se dirigió a Bretón de los Herreros y, en uno de los párrafos de su carta, dice: "Mi designio había sido sugerir las correcciones necesarias o probables que necesita el texto, que son muchas; manifestar el verdadero carácter de su versificación, que, a mi juicio, no ha sido suficientemente determinado, exajerándose por eso la rudeza y barbarie de la obra, y aun suplir algunos de los versos que le faltan, con no poco detrimento de su mérito. Me ha servido para esto último, como para otros objetos, el cotejo prolijo del Poema con la llamada Crónica del Cid, publicada por fray Juan de Velorado, y que hubiera deseado también hacer con la Crónica General atribuida al rey Alfonso el Sabio, que desgraciadamente no he podido haber a las manos."

El motivo de la carta de Bello era, pues, tratar de obtener un ejemplar de la Crónica General, de la que no tenía sino fragmentarias noticias recogidas durante su estancia en Londres. Habría deseado ardientemente también consultar aquellos preciosos códices escurialenses, de los cuales hallo muestras en las notas que el Padre Scio puso a su traducción de la Biblia en lengua romance. Pero no estuvo afortunado Bello en esta gestión, ya que, según se presume, jamás recibió de Bretón de los Herreros ni una sílaba en respuesta a su carta. Bello debió limitarse, por una parte, a sus apuntes tomados en el Museo Británico, y, por otra, a los fragmentos intercalados por el Padre Scio en la obra mencionada.

En 1865 muere Bello, quedando su trabajo sobre el Cid inédito. Dieciséis años más tarde fue hallado por sus herederos y publicado en la forma en que lo dejara su autor.

Cabe preguntarse de qué índole eran los reparos que Bello hacía a la edición de Sánchez, para establecer la finalidad que perseguía al emprender la gigantesca tarea. En seguida, no deja de tener interés saber con qué medios contaba para llevar a buen término su empresa. Y, finalmente, conviene precisar los resultados que obtuvo en sus cuarenta y tantos años de labor ininterrumpida en esta materia.

En cuanto al primer punto, esto es, en cuanto a los propósitos de su obra, $y$ aun en lo referente a su plan y fuentes de investigación, nada y nadie nos lo explica mejor que el propio Bello en el Prólogo a su edición del Poema del Cid:

Sensible es que de una obra tan curiosa no se haya conservado otro antiguo códice que el de Vivar, manco de algunas hojas, i en otras retocado, segun dice Sanchez, por una mano poco diestra, a la cual se deberán tal vez algunas de las erratas que lo desfiguran. Reducidos, pues, a aquel códice, o por mejor decir, a la edición de Sanchez que lo representa, i deseando publicar este Poema tan completo i correcto como fuese posible, tuvimos que suplir de algun modo la falta de otros 
manuscritos o impresos, apelando a la Crónica de Rui Diaz, que sacó de los archivos del monasterio de Cardeña i publicó en 1512 el abad Fr. Juan de Velorado...

La Crónica suministra una glosa no despreciable de aquella parte del Pooma que ha llegado a nosotros, i materiales abundantes para suplir de alguna manera lo que no ha llegado. Con esta idea, i persuadidos tambien de que el Poema, en su integridad primitiva, abrazaba toda la vida del héroe, conforme a las tradiciones que corrian (pues la epopeya de aquel siglo, segun ya se ha indicado, era ostensibłemente histórica, i en la unidad i compartimiento de la fábula épica nadie pensaba), discurrimos seria bien poner al principio, por via de suplemento a lo que allí falta, i para facilitar la intelijencia de lo que sigue, una breve relación de los p-incipales hechos de Rui Diaz, que precedieron a su destierro, sacada de la Crónica a! pie de la letra. E1 cotejo de ambas obras, el estullio del lenguaje en ellas i en ntras antiguas, $i$ la atencion al contexto, me han llevado, como por la mano, a la verdadera leccion e interpretacion de muchos pasajes. Pero sólo se han introducido en el texto aquellas correcciones que parecieron suficientemente probables, avisan. do siempre al lector, $i$ reservando para las notas las que tenian algo de conjetural o de aventurado...

Comprenden las notas, fuera de lo relativo a las variantes, todo lo que creí seria de alguna utilidad para aclarar los pasajes oscuros, separar de lo autentico lo fabuloso i poético, explicar brevemente las costumbres de la edad media i los puntos de historia o jeografía que se tocan con el texto; para poner a la vista la semejanza de lenguaje, estilo i conceptos entre el Poema del Cid $i$ las jestas de los antiguos poetas franceses; $i$, en fin, para dar a conocer el verdadero espíritu $i$ carácter de la composición, i esparcir alşuna luz sobre los oríjenes de nuestra lengua i poesía...

Todo termina con un glosario, en que se ha procurado suplir algunas faltas $i$ correjir tambien algunas inadvertencias del primer editor. Cuanto mayor es la autoridad de don Tomas Antonio Sanchez, tanto mas necesario era refutar algunas opiniones $i$ explicaciones suyas que no me parecieron fundadas; lo que de ningun modo menoscababa el concepto de que tan justamente goza, ni se opone a la gratitud que le debe todo amante de nuestras letras por sus apreciables trabajos (Bello, obra citada. Santiago, 1881, II, págs. 27-30).

En resumen, imagina que el Códice de Vivar - v la edición de Sánchez que lo representa- constituyen meros fragmentos de la primitiva obra de juglar, y se propone, en primer término, informar sobre lo "no hallado". Por otra parte, procura corregir la versión de Sánches para dar la verdadera lección e interpretación del texto. Estas enmiendas fueron hechas, en su mayoría, antes de 1834. Ilustra al lector sobre lo circunstancial y lo profundo del Poema con respecto a la historia y geografía españolas y a la lengua y literatura de la época. $Y$, finalmente, añade un "Glosario", encaminado a reparar errores e inadvertencias de Sánchez.

Si se compara el texto del Códice de Vivar tal como lo ofrece Sánche? (1779) con el de la edición corregida nor Bello (pub1. 1881). se ohcervan de inmediato las muchas enmiendas introducidas por este último. Bello dio, en múltiples casos, nuevo orden y disposición a los versos, ora lle- 
nando lagunas, ora desechando líneas, a su juicio, espurias, para acercarse en lo posible — como dice (el corrector de pruebas) (Baldomero Pizarro)a la forma que probablemente ofrecía el Poema antes de pasar por manos de copistas. En general, Bello alarga el texto, pues la edición paleográfica de Janer cuenta 3.735 versos, la de Sánchez diez más y la de Bello 61 versos más; en cambio, la edición crítica de Menéndez Pidal llega sólo a $\mathbf{3 . 7 3 0}$ versos.

Además, Bello uniforma la ortografía y somete la métrica del Cantar a un severo análisis, ateniéndose a esta conclusión crítica : el Poema pertenece a aquellos que fueron escritos cen estrofas monorrimas de versos largos asonantados, de un número variable de sílabas, con una cesura en medion (o. c., II, pág. 79).

En su Prólogo dice textualmente: "No creo se haya advertido hasta ahora que la Jesta de Mio Cid está escrita en diferentes géneros de metro. El dominante es, sin duda, el alejandrino de catorce sílabas, en que compuso sus poesías Gonzalo de Berceo; pero no puede dudarse de que con este verso se mezcla a menudo el endecasílabo $i$ algunas veces el enneasílabol) (pág. 22) ${ }^{1}$.

Con esta última fórmula concuerdan casi todos los críticos posteriores (Hinard, Restori, Milá. Lidfors, Hanssen, etc.) hasta Menéndez Pidal, sin llegar, sin embargo, a una solución completamente satisfactoria del problema, es decir, sin poder indicar la razón de la irregularidad métrica del Cantar.

Los autores que se han ocupado del mismo asunto con posterioridad al maestro español han vuelto a insistir, en parte, en una versificación rítmica o dinámica (Hills, Grossmann), sin lograr mayor eco en los círculos de los especialistas.

Por lo que respecta a las fuentes relacionadas con el Poema del Cid, era de figurarse que el estudioso que se aventuraba solo a tan gigantesca tarea contara, por lo menos, con toda clase de elementos bibliográficos para realizarla. Sin embargo, no era así. Con excepción de la Crónica de Ruy Díaz que pudo consultar (in extenso", Bello no dispuso, prácticamente, de otras fuentes. Se sirvió además, hasta donde le fue posibłe, según ya dijimos, de los apuntes tomados en el Museo Británico sobre la Crónica general y de las informaciones que le proporcionó la mencionada obra del Padre Scio. En cambio, ignoró nor completo la existencia del precioso códice llamado Crónica de Veinte Reves, explotado en forma magistral por don Ramón Menéndez Pidal.

1 En lugar de estas tres clases de versos, Menéndez Pidal comprobó la existencia de 52 clases, aunque sólo tres aparecen en una proporción mayor del 10 por 100. 
Si examinamos ahora los frutos de su labor, cotejándolos con sus puntos de vista ideales, aquellos que tuvo presentes al emprender la obra, hay que admitir que, en cuanto a su aspiración de completar el texto del Poema, no logró éxito. Partía de una premisa falsa, pues creía que el Cantar abarcaba primitivamente toda la vida del héroe (véase cita del Prólogo, arriba).

Bello concedió, en verdad, excesiva importancia a la Crónica particular del Cid y llegó a imaginarse que esta última representaba una prosificación menos adulterada del Poema que la que habría servido de modelo al copista Per Abbat.

La misma opinión era sustentada todavía en 1891 por el famoso filólogo Cornu. Esta idea es la que le induce a copiar, en el Prólogo de su obra, la parte de los hechos de la vida del Cid anteriores a su destierro. Pensaba suplir, de este modo, la hoja perdida.

$Y$ a continuación hace un ensayo por medio de "obvias i verosímiles alteraciones" de acomodar lo que ofrece el cronista a la forma del Poema hasta llegar a las palabras de los primeros versos del códice de Vivar (Prólogo, págs. 80-83).

Guiado únicamente por la Crónica particular del Cid (a la que consideraba versión menos alterada del Cantar que la que nos ofrece la copia de Per Abbat), Bello tuvo que errar a veces en sus enmiendas. De ahí que Menéndez Pida1, al criticar la posición de éste frente a dicha Crónica, hable de las "desastrosas consecuencias que se derivaron de su lectura para las correcciones del texto", aludiendo, en particular, a las enmiendas introducidas nor Bello en los versos 3 y 40.

En cuanto a las correcciones al texto presentado por Sánchez, Bello estuvo, en numerosos casos, muy afortunado. Esto lo reconoce juez tan severo como el propio don Ramón Menéndez Pidal, quien, en su monumental edición de 1908, después de recalcar las particulares dificultades que entraña la crítica del Poema del Cid y después de recordar aue Bello fue el primero aue intentó la reconstrucción de él, agrega : "Tal edición es hoy todavía muy estimabie nor haber comnrendido mejor que las siguientes el sistema de asonancias que introduce en el texto de Sánchez.) (ITI. nág. 1617).

No obstante, indica, a la vez, que las princinales fallas que él descubre en la exposición de Bello, señalando como tales el considerar el lenguaje del Cantar como de comienzos del siglo xirr y el servirse de las Crónicas muy inoportunamente, son defectos — como dice- -en parte explicables, teniendo en cuenta que se trata de un trabajo antiguo, inacabado, y que no representa el pensamiento maduro ni las últimas ideas del autor) ( $i b$.$) .$ 
Esto no impide que el mismo don Ramón Menéndez Pidal adopte en numerosas oportunidades las explicaciones de Bello, y para ver hasta qué punto apreciaba las glosas, las enmiendas y los comentarios exegéticos del ilustre venezolano basta con fijarse en las innumerables citas en que aparece el nombre de Bello, sobre todo en el aparato crítico de la edición en referencia. Acepta Menéndez Pidal la corrección de Bello en muchísimos versos; por ejemplo: $55,72,136,175,228$, etc.

En algunos pasajes dice: "Mi corrección coincide en lo esencial con la de Bello" (Obras, II, pág. 212 (vv. 232-233); o "E1 lector moderno acaso preferiría la corrección de Bello...) (v. 274), etc.

En varios casos, don Ramón Menéndez Pidal aprovecha igualmente los datos y explicaciones de Bello en su Vocabulario (III). Cp. las voces descubrir (Bello, II, pág. 288), engramear (Bello, II, pág. 201), paz (Bello, II, pág. 291), quiñonero (Bello, II, pág. 402), villa (Bello, II, pág. 208), vocaçión (Bello, II, pág. 266).

$\mathrm{Y}$ Bello lo habría hecho, sin duda, mejor aún si aquella edición paleográfica de Janer, publicada en el tomo 57 de la colección Rivadeneira, en lugar de aparecer en 1864, es decir, pocos meses antes de la muerte de Bello, hubiera llegado a sus manos algún tiempo antes. Pues, ciertamente, Bello no habría dejado de introducir en su obra enmiendas que le sugiriera la edición paleográfica. Por lo menos, el conocimiento de esta obra, casi en la víspera de su muerte, debe de haberle proporcionado la gran satisfaccion de comprobar sus aciertos.

Una confirmación de esta índole debió ser para Bello motivo del más justo orgullo. Sin embargo, era de un natural tan modesto que, al apreciar su propio trabajo, declara en las Notas a la Crónica: "Yo no pretendo que el texto de la Crónica i mis conjeturales enmiendas restablezcan exactamente el de la Jesta; aunque no es imposible que hayan acertado alguna vez a reproducirlo" (Prólogo, pág. 83).

La edición chilena de 1881 , hecha bajo la dirección del Consejo de Instrucción Páblica, en cumplimiento de la ley de 5 de sentiembre de $\mathbf{1 8 7 2}$, como volumen II de las Obras completas de Andrés Bello, es hasta hoy la Gnica del trabajo de Bello. Hubo un intento de reeditarlo en Madrid, poco después de la primera publicación chilena, como anota don Pedro Grases, uno de los mejores conocedores actuales de la producción literaria de Bello, pero tal proyecto fracasó. Incluso don Miguel Antonio Caro había hecho gestiones desde Bogotá para que don Rufino José Cuervo escribiera un prólogo a esa edición. Sin embargo, después de reiterada insistencia de parte de Caro, don Rufino le contestó en marzo de 1886, diciendo: "Sobre el Cid de Bello le diré lo que pienso. Como edición de un 
monumento literario de que no existe sino un manuscrito, no puede servir la obra de Bello. E1 trabajo de él es una restauración conjetural que con sus anotaciones tiene importancia como comentario; pero el valor de uno y otro no puede estimarse sino en vista de una reproducción exacta del códice Por lo mismo creo que, si se pensase en reimprimirle, habría que poner juntos los dos textos. Ahora yo le diré que para saber el efecto que así pueda producir necesitaría dedicar algunos días para examinarlo, y ésa habría de ser la materia del prólogo. Usted ve que el punto es espinoso, y aun no le doy el sín (P. Grases, Andrés Bello. El primer humanista de América, pág. 100).

De esta manera habrá terminado, probablemente para siempre. el intento de reeditar dicho trabajo, ya aue la edición de don Ramón Menénder. Pidal, de 1908 (la segunda edición, 1944, es una reimpresión de la primera con sólo ligero retocue), puede considerarse como definitiva y hace innecesaria la reproducción de cualquiera de las anteriores.

De todos modos, y aunque ohra de autodidacta, ha de calificarse de verdaderamente admirab!e la de Bello, siendo prueba manifiesta de oue el sabio venezolano tenía una concención perfecta de lo que debió ser el Poema en el bensamiento del juglar, tanto con respecto a su contenido como a su forma. Bello no quedó satisfecho con su trabajo, ya que deseaba, hasta el altimo momento de su vida, procurarse los medios adecuados para perfeccionarlo antes de darlo a la estampa.

No obstante, aun así, inconcluso como tuvo que quedar, es un testimonio evidente de la capacidad crítica de uno de los filólogos más preclaros del Nuevo Mundo.

RODOLFO ORO7.

\section{Santiago de Chile}

